\title{
PREVENTION OF RISK FACTORS OF CARDIOVASCULAR DISEASE IN NURSING
}

\author{
Mária Novysedláková, ${ }^{1}$ Róbert Šeliga²
}

\begin{abstract}
:
Introduction: Cardiovascular disease, in terms of its frequency, the severity of organ damage, and the consequences for the health of the population constitutes one of the most pressing problems of our population. The prevention of subsequent coronary events and the maintenance of physical functioning in such patients are a major challenge in preventive care. However, many patients opt for a change in their lifestyle, some with the support of a health professional.

Objective: This empirical survey focuses on the knowledge of respondents about preventing cardiovascular disease. Statistical methods determine the differences between males and females in attending preventive check-ups, understanding and observing risk factors in their lifestyle, and having an interest in changing their lifestyle.

Methods: The survey uses a non-standardized questionnaire. Apart from demographic data, the questionnaire had 10 items assessing the respondent's knowledge of risk factors for cardiovascular disease, 10 on lifestyle and attitudes to the change in lifestyle, and five regarding their interest in education about the subject. Exploratory data includes answers from 70 respondents, who were outpatients in a general practitioner's department. Of these, 32 are males (46.0\%) and 38 are females (54.0\%). Results of the survey are analyzed using the Chi-Squared test.

Results: Fifty-four of the 70 respondents $(55.7 \%$; 20 males and 34 females) undertake preventive check-ups at the general practitioner's department at least once in two years. No significant differences present between males and females in attending preventive check-ups $\left(\chi^{2}=3.455 ; \mathrm{df}=1 ; P=0.05\right)$ and in showing a willingness for a lifestyle change $\left(\chi^{2}=1.789\right.$; $P=0.05)$. However, based on the given data, a significant difference presents between males and females regarding proper regime observance $\left(\chi^{2}=18.651 ; \mathrm{df}=1 ; P=0.05\right)$. For example, females know the observance of a healthy diet is necessary for preventing ischemic heart disease $\left(\chi^{2}=20.124 ; \mathrm{df}=1 ; P=0.05\right)$.

Conclusion: The study shows that the difference between males and females is significant regarding their understanding of risk factors related to lifestyle and proper regime observance. Thus, education could lead to reducing or eliminating such risk factors. Prevention of risk factors is complex and lifelong. Under conditions of the Slovak health service, registered nurses are responsible for the education of patients.
\end{abstract}

UDC classification 615.8; 314.11; DOI: http://dx.doi.org/10.12955/cbup.v5.1057

Keywords: Cardiovascular disease, risk factors, lifestyle, nursing.

\section{Introduction}

The frequency of cardiovascular disease and subsequent severity of organ damage and other population health consequences constitute some of the most pressing problems for our population (Studenčan, 2006). Cardiovascular disease contributes to 53\% of total mortality and is a major cause of the shorter life expectancy evident in Slovakia. On average, the share of the total number of deaths in 2011-2014 attributed to cardiovascular disease was approximately 52-55\%. From the number of people who died from circulatory diseases, $15.8 \%$ were younger than 65 years, with every three premature deaths of men accounting for one death of a woman (Report on the State, 2015).

\section{Literature review}

Diseases of the circulatory system occur 3-4 times higher in males than females. Though, with age, the incidence of coronary heart disease increases for both males and females with post-menopausal females displaying the same incidence as males. Given the prevalence of the disease, it is necessary to devote considerable effort towards its prevention, with early recognition through commencing pathological processes. Today, risk factors for coronary heart disease can be divided into two main groups:

- Uncontrollable, depending on age, gender, and genetic factors; and

- Influenced, by high LDL cholesterol to low HDL cholesterol, smoking, diabetes, obesity, physical inactivity, mental stress, increased blood pressure, and alcohol.

Their treatment, according to Riečanský (2009) is carried out on several levels:

\footnotetext{
${ }^{1}$ Catholic University in Ruzomberok, Faculty of Health Care, Slovak Republic, maria.novysedlakova@ku.sk

${ }^{2}$ Catholic University in Ruzomberok, Faculty of Health Care, Slovak Republic, robertseliga@ centrum.sk
} 
Halting or slowing the process of atherogenesis through an appropriate intervention using diet, physical activity, no smoking, and administration of appropriate medicines. Diet should include plenty of vegetables and fruits, fish and poultry, and exclude foods that are rich in cholesterol and saturated fatty acids. For obese individuals, it is indicated for the reduction of body weight. Also important is reducing the consumption of alcoholic beverages and improving blood flow to the ischemic heart muscle by administration of appropriate medicines.

Preventing the possible closure of the vessel by a blood clot through administration of drugs that inhibit blood clotting.

Mechanical treatment of coronary arteries through angioplasty or Cardiac revascularization with health-promoting behaviors, for research purposes, integrated into an individual's lifestyle.

The role of nursing is to influence the health of the population from early childhood to advanced age. An individual's behavior, according to (Štejfa et al., 2007, p. 242), depends on various factors:

Individual knowledge, skills, and personal motivation; Factors of the microcosm in which the person lives, e.g., family, friends, financial conditions and social background; and Macrocosm factors that advise the economic and political system, government organizations, national and cultural traditions, communication media, and finally, world globalization.

The ability to understand, predict, control, and change the behavior of an individual regarding their health remains problematic. Health-supporting behavior, for research purposes, is integrated into the lifestyle of an individual (Mendes, 2011).

The prevention of subsequent coronary events and the maintenance of physical functioning in affected patients are a major challenge in preventive care (Ades, 2001). Particular attention should be paid to the elements of a can use numerals for these numbers as this makes them consistent with the others in this paragraph.

Some major risks are modifiable in that they can be prevented, treated, and controlled. There are considerable health benefits at all ages, for both men and women, in stopping smoking, reducing cholesterol and blood pressure, eating a healthy diet and increasing physical activity (Alina, 2013).

The nurse is important in educating the population about health matters. A nurse helps individuals to change behavior by providing ongoing support for information, advice, and lessons, as well as assessing the motivations of their actions and behavior (Novysedláková, Hudáková, \& Kozáková, 2015). Strengthening health is characterized as 'behaviors' that pursue a certain goal and progresses to health promotion as a process of increasing the ability of people to influence and improve their health.

The aim of this survey is to establish whether respondents understand the risk factors of their lifestyle and about cardiovascular diseases and preventive measures that lead to their reduction or total elimination. Statistical methods are used to determine the differences in attendance of preventive checkups, the knowledge and observance of risk factors of lifestyle, and the interest to change lifestyle based on gender.

\section{Data and Methodology}

Exploratory data were obtained from 70 outpatients in a general practitioner's department. Respondents were classified by gender, age, and the presence of a minimum of one risk factor for cardiovascular disease. From a total number of 70 respondents, there were 14 of the age 18-30 years (27.9\%), 20 of the age $31-45$ years (28.9\%), and 36 respondents of 46 and more years $(50.9 \%)$.

Altogether, 32 male $(45.8 \%)$ and 38 female $(53.9 \%)$ participated in the survey. Adjusting for education showed there were 10 respondents with primary education (13.8\%), 42 respondents with secondary education $(60.1 \%)$, and 18 respondents accomplished university education (25.7\%).

The survey was carried out using a non-standardized questionnaire. Apart from demographic information and data about blood pressure, body weight, and height, it contained ten items for

assessing knowledge of risk factors for cardiovascular disease, ten for lifestyle and the attitude towards changing lifestyle, and five regarding respondents' interest in education about the subject.

The survey was carried out from December 2012 to January 2013 in a general practitioner's outpatients' department of a non-state health institution. 
Results of the survey were statistically evaluated using the chi-squared test using Microsoft Excel version 2013 with the add-on function, CHIINV, which calculates the inverse of the right-tailed probability of the chi-square distribution. At $5 \%$ level of probability, the critical $\chi^{2}$ for one degree of freedom (df) was 3.841, as determined using the CHIINV.

Our hypothesis: In these files, there is a significant difference (chi.q>chi.q.crit) between male and female in the measures taken to reduce cardiovascular disease. Critical differences between men and women were regarding attendance for preventive check-ups and proper regime observance to reduce cardiovascular disease.

\section{Results and Discussion}

Regular fifty-four respondents of the total $70(55.7 \%)$ at least once in two years. The chi-squared result was 3.455 (df: 1; critical value: 3.841) (Table 1), there was no significant difference between men and women based on the collected data in participating in preventive checkups.

Table 1: Regular attendance for preventive check-ups

\begin{tabular}{|c|c|c|c|c|c|}
\hline & $\begin{array}{l}\text { Regular } \\
\text { attendance }\end{array}$ & & $\begin{array}{l}\text { Do not regular } \\
\text { attendance }\end{array}$ & \multirow[b]{2}{*}{ Expected (E) } \\
\hline & & Observed (O) & $\begin{array}{l}\text { Expected } \\
\text { (E) }\end{array}$ & Observed $(\mathrm{O})$ & \\
\hline \multirow[t]{3}{*}{ Counts } & Male & 20 & 24.685 & 10 & 7.314 \\
\hline & Female & 34 & 29.314 & 6 & 8.685 \\
\hline & Total & 54 & & 16 & \\
\hline \multirow[t]{2}{*}{$(\mathrm{O}-\mathrm{E})^{2} / \mathrm{E}$} & Male & 0.889 & & \multicolumn{2}{|c|}{0.986} \\
\hline & Female & 0.748 & & \multicolumn{2}{|c|}{0.830} \\
\hline \multicolumn{5}{|c|}{ Chi-squared $=3.455$} & \\
\hline & \multicolumn{4}{|c|}{ Critical value $=3.841$} & \\
\hline \multicolumn{5}{|l|}{$\mathrm{Df}=1$} & \\
\hline
\end{tabular}

We present other survey of results. Eleven respondents (15.7\%) indicated that they would be at risk of cardiovascular disease; $17(24.3 \%)$ chose more likely than not; 30 (42.9\%) could not assess either way; $5(7.1 \%)$ were convinced they were less likely to be at risk; $3(4.3 \%)$ answered that they were not at risk of cardiovascular diseases occurring; and $4(5.7 \%)$ were being treated for cardiovascular disease at that time. Twenty respondents (28.6\%) answered they knew of the medical examination for which they were entitled under the terms of a preventive checkup; while 25 respondents $(35.7 \%)$ were unaware, and 25 respondents (35.7\%) relied on the decision of the general practitioner.

Cardiovascular disease occurred in the family of 37 respondents $(52.9 \%)$. It did not occur in 20 respondents (28.6\%), and 13 respondents (18.6\%) did not know about the occurrence of cardiovascular disease in their families. For changes in lifestyle for cardiovascular risk were motivated $43.9 \%$ respondents.

Preventive checkups are itemized in Act N ${ }^{\circ} 577$ of 2004 of the Statute Book on Health Care Extent. Although health insurance companies completely finance them, the majority of people do not complete their check-ups. The Act on Health Care Extent lists 15 different preventive check-ups.

According to the statistical data of health insurance companies, female, in general, are more disciplined than men in completing the checkups. Women in the productive age range of 35-45 years appear to approach preventive checkups most responsibly. People with higher education also complete them more often. The majority of the population, however, does not feel obliged to complete such.

According to Framingham (2002, pp. 3068-3072), the risk of ischemic heart disease occurring at age 40 years is $21 \%$ for a male and $20 \%$ for a female. Prognostication is serious for a population with risk factors. The incidence of diseases of the circulatory system are 3-4 times higher in males, than in females. With age, the incidence of coronary heart disease increases for both male and female. After menopause, female suffer the same incidence as male. For the working-age population, coronary heart 
disease is a recognized disability, but significantly more so for male than female (Report on the State, 2015). Individuals with relatives displaying pre-existing ischemic disease (male $<55$ years, female $<65$ years) have an increased risk of developing coronary artery disease and should have their risk factors evaluated (Riečanský, 2009). Family and personal history fall into the category of 'uncontrollable' risk factors. It is also likely that intra-uterine effects on the fetus such as smoking or inadequate maternal nutrition during pregnancy may be significant. The family history of male under 55 years of age and female under 65 with premature ischemic cardiovascular disease is an independent risk factor (Štejfa et al., 2015).

Regarding knowledge about risk factors for coronary heart disease, the chi-squared result was 18.651

(Table 2) and higher than the critical value at the 0.05 probability. Thus, there was a significant difference between male and female in this respect.

Table 2: Knowledge about risk factors for coronary heart disease

\begin{tabular}{|c|c|c|c|c|c|}
\hline & $\begin{array}{c}\text { They have } \\
\text { knowledge (n) }\end{array}$ & & $\begin{array}{c}\text { They do not } \\
\text { have } \\
\text { knowledge (n) }\end{array}$ & \\
\hline & & Observed $(\mathrm{O})$ & $\begin{array}{l}\text { Expected } \\
\text { (E) }\end{array}$ & Observed (O) & Expected (E) \\
\hline \multirow[t]{3}{*}{ Counts } & Male & 7 & 16 & 25 & 16 \\
\hline & Female & 28 & 19 & 10 & 19 \\
\hline & Total & 35 & & 35 & \\
\hline \multirow{2}{*}{$(\mathrm{O}-\mathrm{E})^{2} / \mathrm{E}$} & Male & & 5.063 & & 5.063 \\
\hline & Female & & 4.263 & & 4.263 \\
\hline \multicolumn{5}{|c|}{ Chi-squared $=18.651$} & \\
\hline & \multicolumn{4}{|c|}{ Critical value $=3.841$} & \\
\hline \multicolumn{5}{|l|}{$\mathrm{Df}=1$} & \\
\hline
\end{tabular}

The survey results, that describe lifestyle of respondents. Of the total number, 22 respondents $(31.4 \%)$ smoked cigarettes. Three respondents (4.3\%) smoked 0-5, nine (12.9\%) 6-10, three (4.3\%) 11-15, and five $(7.1 \%)$ more than 15 cigarettes daily. Thirty-three respondents $(47.1 \%)$ participated in sports activities in their free time. Twenty-eight respondents $(40.0 \%)$ were aware of the dietary intake suitable for reducing the risk of cardiovascular disease, and 21 respondents $(30.0 \%)$ mostly knew. A body mass index higher than 29 was determined in $(41.4 \%)$ of respondents.

There remains a risk for heart disease in Slovak population. It was found that, regarding the four most serious risk factors, $25 \%$ of the population show no risk, more than $33 \%$ display one, $25 \%$ two, $8 \%$ three and $1 \%$ all four factors. According to the Social Insurance Agency in Slovakia, the leading cause of disability in 2016 regarding civilization diseases result from unhealthy lifestyles and diets, lack of exercise, and stress. This is reflected particularly in male, in whom up to $15 \%$ of disability cases is caused by diseases of the circulatory system. In general, the risk of ischemic heart disease is higher in male than in female, mainly in male at a younger age; male in middle age already have a high occurrence of the main risk factors. More often they suffer from an abdominal type of obesity and metabolic syndrome. Health consultations first visited 1590 smokers, of which 598 were male and 992 female. Of these 1590 smokers, $22 \%$ of the highest smoking prevalence was in the age group 20-24 years in the male or 25-34 years in female. In the ages, 25-64 years, optimum weight occurred in $35.1 \%$ of male and $43.2 \%$ female. Overweight and obesity was observed in $64.6 \%$ of male and $54.9 \%$ female (Report on the State, 2015). The difference in the incidence of coronary artery disease decreases with change in lifestyle away from high consumption of cigarettes, alcohol, and oral contraceptives, and the changing role and position of women in modern society (Riečanský, 2009, p. 71).

For lifestyle measurements, the chi-squared result was 20.124 (Table 3), which is greater than the critical value of 3.841 for the 0.05 probability. Hence, the result is statistically significant. The given 
data was significantly higher among female, who know observance of a healthy diet is necessary for the prevention of ischemic heart disease.

Table 3: Measures in lifestyle that reduce the risk of cardiovascular disease

\begin{tabular}{|c|c|c|c|c|c|}
\hline & & $\begin{array}{c}\text { Reduce the } \\
\text { risk }\end{array}$ & & $\begin{array}{l}\text { Do not reduce } \\
\text { the risk }\end{array}$ & \\
\hline & & Observed (O) & Expected (E) & Observed $(\mathrm{O})$ & Expected (E) \\
\hline Counts & Male & 12 & 28.343 & 6 & 3.657 \\
\hline & Female & 50 & 33.657 & 2 & 4.343 \\
\hline & Total & 62 & & 8 & \\
\hline$(\mathrm{O}-\mathrm{E})^{2} / \mathrm{E}$ & Male & & 9,424 & & 1,501 \\
\hline & Female & & 7,936 & & 1,264 \\
\hline Chi-square & $=20,12$ & & & & \\
\hline & Critica & value $=3.841$ & & & \\
\hline $\mathrm{Df}=1$ & & & & & \\
\hline
\end{tabular}

Regarding interest in changing lifestyle, the chi-squared results of 1.789 (Table 4) was less than the critical value for a 0.05 probability. Thus, there was no significant difference between male and female. Interested in changing their current lifestyle were thirty-six respondents (51.4\%), 29 responded $(41.4 \%)$ they were more likely to than not, five responded (8.0\%) they could not assess it.

The number of deaths from injuries increases with age, up to the age of 64 years. This occurs mainly at age 15 years, where death among boys and male is 3-6 times higher than girls and women for higherrisk models in their behavior.

Table 4: Interest in changing lifestyle

\begin{tabular}{|c|c|c|c|c|c|}
\hline & & Interest & & $\begin{array}{c}\text { Do not } \\
\text { interest }\end{array}$ & \\
\hline & & Observed (O) & Expected (E) & Observed (O) & Expected (E) \\
\hline Counts & Male & 25 & 29.714 & 3 & 2.286 \\
\hline & Female & 40 & 35.286 & 2 & 2.714 \\
\hline & Total & 65 & & 5 & \\
\hline$(\mathrm{O}-\mathrm{E})^{2} / \mathrm{E}$ & Male & & 0.748 & & 0.223 \\
\hline & Female & & 0.629 & & 0.188 \\
\hline Chi-square & $=1.789$ & & & & \\
\hline & Critica & value $=3.841$ & & & \\
\hline $\mathrm{Df}=1$ & & & & & \\
\hline
\end{tabular}

Source: Authors

Slovakia may obtain representative data on the prevalence of both risk factors in repeated screenings of population health, under the World Health Organization, Program of Countrywide Integrated Noncommunicable Disease Intervention. This data is a national study of health surveillance for the years 1993, 1998, 2003, and 2008 that uses international criteria. The European Health Examination Survey (EHES) Act 2011-2012 is a product of the activities of counseling centers for the protection and promotion of health (referred to as 'health counseling') within the framework of individual interventions of clients interested in their health (Report on the State, 2015). Primary efforts focus on the control of reversible coronary risk factors atherosclerosis. Clients are to avoid smoking and 
commence effective control of hypertension, diabetes, and hyperlipoproteinemia. Modifying lifestyle involves a change in eating habits, increasing physical activity, and easing mental stress by practicing relaxation techniques. An ideal approach is a comprehensive one that deals with all risk factors (Ades, 2001). Changing dietary intake, introducing regular physical activity, and converting to non-smoking will reduce cardiovascular risk in the adult population by as much as $30 \%$, and significantly improve an individual's control over developing heart and blood vessel diseases (Riečanský, 2009, p.71).

This research examining the differences between males and females found that it was difficult to separate innate types of behavior from learned or to understand the extent to which stereotypes affect the perception of individuals and the behavioral or cognitive differences between the sexes. The research shows that compared with existing similarities between males and females the extent of these differences is minimal (Gender Differences, 2010, pp. 42-51). Changes in the lifestyle of a patient with ischemic coronary or other atherosclerotic disease depend on his or her willingness to modify his or her behavior. Many patients choose to make a change in their lifestyle and often with the support of a professional health worker or family.

\section{Conclusion}

Research results revealed significant differences between male and female knowledge of lifestyle risk factors and proper regime observance. Results of scientific research indicate that with a change towards nutrition, regular physical activity, and non-smoking, the risk of cardiovascular disease in the adult population could reduce by $30 \%$ and thus, help control the advancement of cardiovascular diseases. Human health and behavior cannot be separated. Since many of the current generation of citizens are prone to illnesses from an improper lifestyle, a change towards healthy lifestyle habits and shifts in behavior can have an immense role in health protection. A greater emphasis on studying human behavior towards health would help improve overall public health. The nurse who achieved a professional qualification for a medical occupation, apart from tending care, assists in protecting, supporting, and maintaining health along with specialized functions in the sphere of health education and instruction and research connected with providing health care.

\section{References}

Ades, P. A. (2001, September 21). Cardiac rehabilitation and secondary prevention of coronary heart disease. The New England Journal of Medicine, 345, (12), 892-902. Retrieved from https://www.ncbi.nlm.nih.gov/pubmed/11565523

Alina, D. B. (2013). Modification of some risk factors in patient with stable angina in treatment with beta-blockers and kalcium channel blockers. Retrieved from

http://protmed.uoradea.ro/facultate/anale/ecotox_zooteh_ind_alim/2013A/imapa/3.Bei\%20Diana1.pdf

De Backer, G. et al. (2003) European guidelines on cardiovascular disease prevention in clinical practice. Third Joint Task Force of European and Other Societies on Cardiovascular Disease Prevention in Clinical Practice. European Heart Journal.24,1601-1610. Retrieved from https://www.ncbi.nlm.nih.gov/pubmed/14555889

Mendes, M. (2011). Cardiac Rehabilitation. In Achieving Optimal treatment. Europen Cardiology,2011, 7, (1), 62-65. Retrieved from https://www.ecrjournal.com/articles/role-cardiac-rehabilitation-achieving-optimal-treatment-0

Novysedláková, M., Hudáková, Z., \& Kozáková, M. (2015). Podpora zdravia v ošetrovatel’stve. [Health promotion in nursing) In Interdyscyplinarny Wymiar opieki Nad Czlowiekem w naukach o zdrowiu. [The interdisciplinary dimension of care over the man in the health sciences]. Editor: Wysza szkola Humanisticzno-Ekonomiczna wo Wloclawku. Wloclawek, 63-66, 199-218.

Riečanský, I. (2009). Aterosklerotické choroby. [Atherosclerotic diseases]. Bratislava: Herba, 252.

Rodové rozdiely vo výsledkoch vzdelávania. (2010). Štúdia o prijatých opatreniach a súčasnej situácii v Európe. Brusel. [Gender differences in results of education]. [Study on approved precautions and current situation in Europe]. Brussels: Eurydice, 42-51.

Správa o zdravotnom stave obyvatel'stva SR za roky 2012 - 2014. 2015. [Report on the state of health of the Slovak population for the years $2012-2014]$. Retrieved from

http://www.uvzsr.sk/docs/info/podpora/Sprava_o_zdravotnom_stave_obyvatelstva_SR_za_roky_2012_2014.pdf

Studenčan, M. (2006). Akútny koronárny syndróm [Acute coronary syndrome]. Kosice: Media Group, 2006, p. 154-162.

Štejfa, M. et al. (2007). Kardiologie [Cardiology] Praha: Grada Publishing, 213-239.

The Framingham heart study (2002). Circulation, 106, (24), 3068-3072. 